\title{
Magnetic Marker Wireless Localisation versus Radioguided Localisation of Nonpalpable Breast Lesions
}

\author{
HL Tsui ${ }^{1}$, EPY Fung ${ }^{2}$, KM Kwok ${ }^{2}$, LKM Wong ${ }^{2}$, LW Lo ${ }^{2}$, WS Mak ${ }^{2}$ \\ ${ }^{I}$ Department of Radiology and Organ Imaging, United Christian Hospital, Hong Kong \\ ${ }^{2}$ Department of Diagnostic and Interventional Radiology, Kwong Wah Hospital, Hong Kong
}

\begin{abstract}
Introduction: Precise preoperative localisation is essential for nonpalpable breast lesions undergoing lumpectomy. Hookwire localisation has been gradually replaced by radioisotope-guided occult lesion localisation (ROLL). We aimed to evaluate the use of magnetic metal markers (Magseed) as a nonradioactive and wireless alternative.

Methods: We compared cases of Magseed localisation performed between September 2018 and April 2020 with the same number of ROLL procedures with identical pathology in the same period.

Results: In total, 24 Magseed and 24 ROLL procedures were included. There were no significant differences between the case groups in terms of target characteristics, operation time, specimen size, pathological diagnosis, margin clearance, or reoperation rate. Localisation duration was significantly shorter in ROLL procedures (8.7 min) compared with Magseed localisation (12.9 min, $p<0.0001)$. No complications were reported. Same-day surgery was performed in all ROLL and 17 Magseed lesions. The localisation-operation interval for the other seven Magseed lesions were 4 to 14 days. Significantly lower intraoperative re-excision rates $(p=0.006)$ were observed in the Magseed group (8.3\%) compared with the ROLL group (45.8\%). Technical success of the ROLL group was 100\%. Twenty-two (91.7\%) Magseed localisations achieved technical success with 11/11 (100\%) using ultrasound and 11/13 (84.6\%) using stereotactic guidance. Magseed displacement was up to $4.8 \mathrm{~mm}$ in the localisation-operation interval. Conclusion: Magseed is a safe and effective localisation technique for nonpalpable breast lesions, which allows decoupling of radiological and surgical schedules.
\end{abstract}

Key Words: Breast/diagnostic imaging; Breast neoplasms/pathology; Carcinoma

Correspondence: Dr HL Tsui, Department of Radiology and Organ Imaging, United Christian Hospital, Hong Kong.

Email: karen.tsuibl@gmail.com

Submitted: 25 Aug 2020; Accepted: 24 Nov 2020

Contributors: HLT and EPYF designed the study. HLT acquired the data. All authors analysed the data. HLT drafted the manuscript. All authors critically revised the manuscript for important intellectual content. All authors had full access to the data, contributed to the study, approved the final version for publication, and take responsibility for its accuracy and integrity.

Conflicts of Interest: All authors have disclosed no conflicts of interest.

Funding/Support: This research received no specific grant from any funding agency in the public, commercial, or not-for-profit sectors.

Data Availability: All data generated or analysed during the present study are available from the corresponding author on reasonable request.

Ethics Approval: This is a retrospective study approved by the local research ethics committee (Reference number: KC/KE-20-0072/ER-1). 


\title{
中文摘要
}

\section{不能觸及乳腺病變的磁性標記物無線定位與放射導向定位的比較}

\author{
徐愷靈、馮寶恩、郭勁明、黃嘉敏、羅麗雲、麥詠詩
}

\begin{abstract}
引言 : 精確的術前定位對於不能觸及乳腺病變切除術至關重要。鈎線定位已逐漸被放射導向隱匿性 病灶定位（ROLL）所取代。我們旨在評估乳腺病灶定位標記物Magseed作為無線及非放射性替代品 的使用。
\end{abstract}

方法：比較2018年9月至2020年4月期間進行的Magseed定位病例與相同數目和病理結果的ROLL病例。 結果 : 納入 24 例Magseed和24例ROLL。兩組在靶點特徵、手術時間、標本大小、病理診斷、切緣 清除率或再手術率等方面均無顯著差異。與Magseed定位相比, ROLL的定位持續時間明顯較短 （12.9分鐘比8.7分鐘，p < 0.0001$)$ 。兩組均無併發症。所有ROLL和17例Magseed病變均在同一天 進行手術, 其餘7例Magseed病變的定位日期與手術日期間隔為4至14天。與 ROLL組相比, Magseed 組減少術中再切除率 $(45.8 \%$ 比 $8.3 \%, p=0.006)$ ROLL組的技術成功率為100\%。22例Magseed定 位取得技術成功（91.7\%），其中 11/11（100\%）使用超聲，11/13（84.6\%）使用立體定向引導。 Magseed位移在定位與手術操作間隔中不多於 4.8 毫米。

結論：Magseed是一種安全有效的定位技術, 用於不能觸及的乳腺病變, 可以將放射學和手術計劃分 開。

\section{INTRODUCTION}

The development of screening programmes for breast cancer has led to a decrease in mortality from breast cancer in women. ${ }^{1,2}$ Improved screening techniques have found increasing numbers of nonpalpable breast cancers/ high-risk lesions. The smaller lesions and earlier stage render patients eligible for breast-conserving treatment. Precise preoperative localisation of nonpalpable breast lesions is essential to achieve accurate diagnosis in suspicious lesions and to obtain adequate excision margins, while avoiding excessive surgical resection in breast-conserving surgery for cancer. ${ }^{3}$ Hookwire localisation was the gold standard and has been gradually replaced by radioisotope-guided occult lesion localisation (ROLL) in recent years. ${ }^{4}$ However, ROLL is limited to centres with a nuclear medicine unit and availability of same-day surgery. New advances in localisation techniques for nonpalpable breast lesions have been introduced, allowing decoupling of localisation and operation schedules. Nonradioactive magnetic metal seeds (Magseed, Endomagnetics Inc., Cambridge, United Kingdom) is one of the new methods. It was approved by the US Food and Drug Administration in 2016 for breast lesion localisation. ${ }^{5,6}$

We aimed to evaluate our initial experience with Magseed localisation of nonpalpable breast lesions with comparison with ROLL, in assessing the feasibility and effectiveness of this novel localisation technique.

\section{METHODS}

This is a retrospective study approved by the local research ethics committee (Ref: KC/KE-20-0072/ER-1). We reviewed all cases of Magseed localisation between 1 September 2018 and 30 April 2020 in a regional hospital, and matched them with the same number of ROLL procedures with identical pathology performed since 1 September 2018. Cases with ROLL with no specimen scintigraphic images were excluded.

Magseed is a paramagnetic steel and iron oxide seed, measuring $1 \mathrm{~mm}$ in diameter and $5 \mathrm{~mm}$ in length (Figure 1). It can be placed in the breast with either ultrasound or stereotactic guidance up to 30 days before surgery as recommended by the vendor (Figures 2 and 3). It received Food and Drug Administration clearance in 2018 for long-term implantation in the US. ${ }^{6}$ The seed is preloaded into an 18-gauge $7-\mathrm{cm}$ or $12-\mathrm{cm}$-long steel needle and is retained by a wax plug. A steel obturator is used to deploy the seed. The seed is detectable using a handheld magnetometer (Sentimag probe, Endomagnetics). The probe generates an alternating magnetic field to magnetise the iron oxide particles within the Magseed temporarily. The magnetic signature 


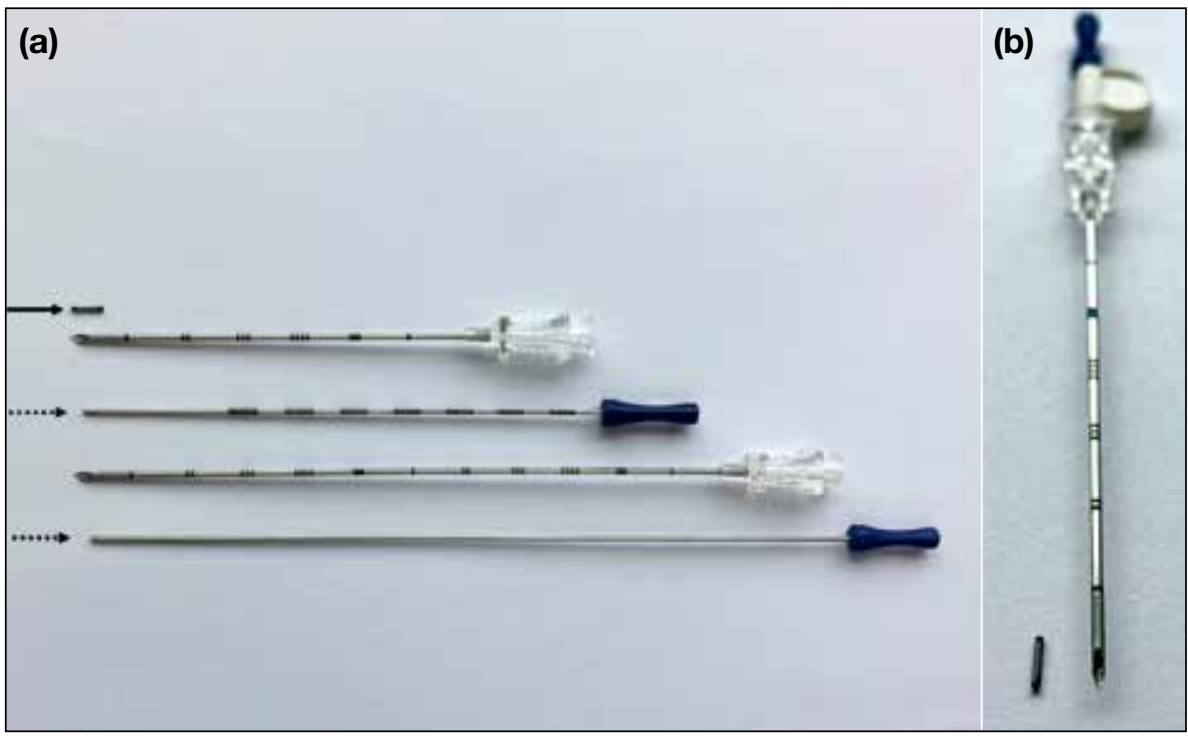

Figure 1. (a) Magseed (arrow) with 7-cm and 12-cm deployment needles and their obturators (dashed arrows). (b) Closeup view of Magseed next to a 7-cm deployment needle.

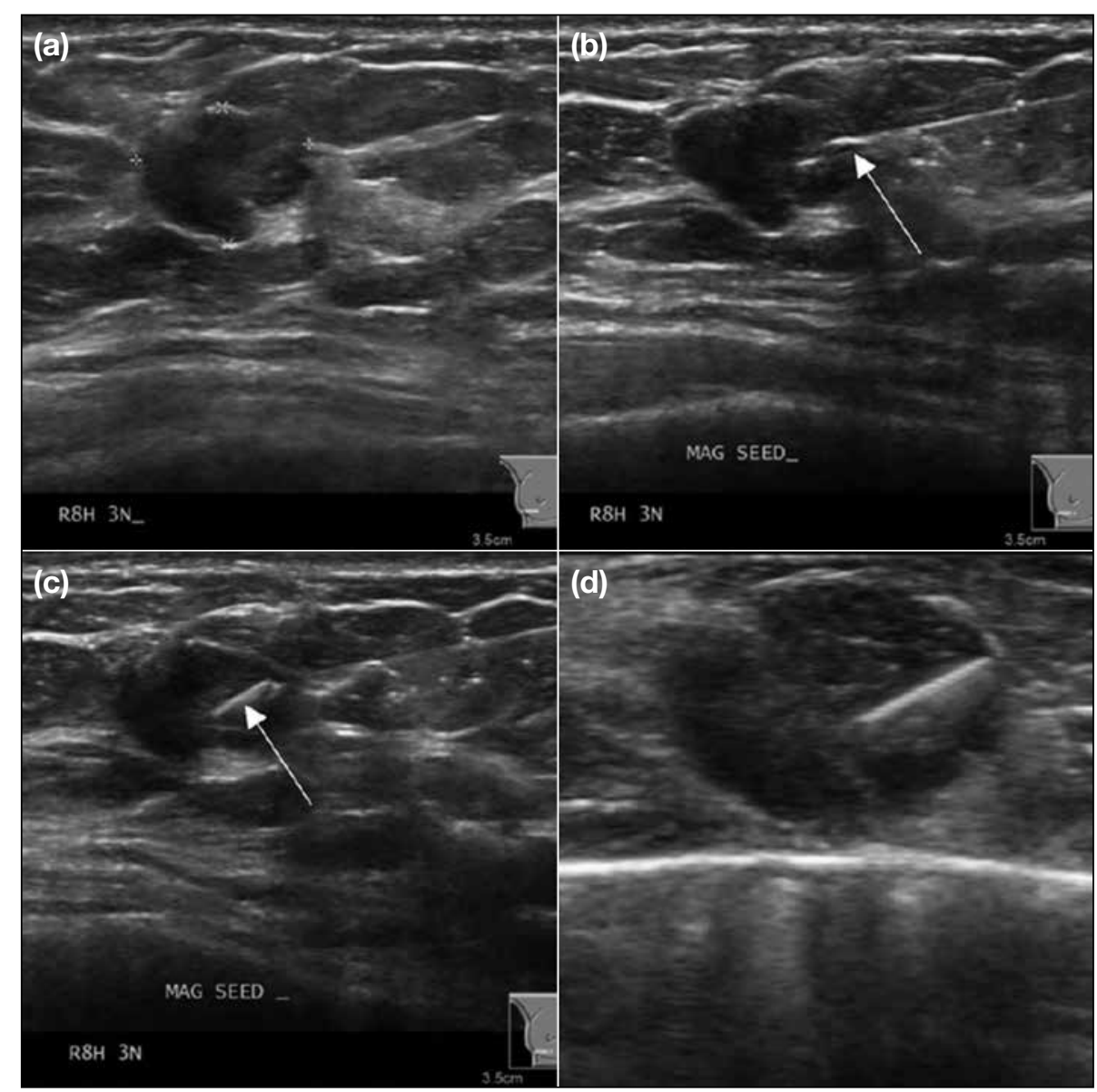

Figure 2. (a) A 60-year-old woman with invasive carcinoma, presenting with a 1.3-cm hypoechoic mass in the lower outer quadrant of right breast. The mass was $0.7 \mathrm{~cm}$ deep. (b) Figure showing Magseed (arrow) placed under ultrasonic guidance with the deployment needle in situ. (c) Magseed (arrow) is deployed within the mass. (d) Specimen ultrasound showing the mass with the Magseed in situ with no displacement. of the Magseed is then detected by the Sentimag probe. The Sentimag unit displays a numerical count and produces an audio tone, related to the strength of the magnetic field, and hence the distance of the seed from the probe.$^{5,8}$ As ferromagnetic instruments will interfere with the signal, special nonferromagnetic 

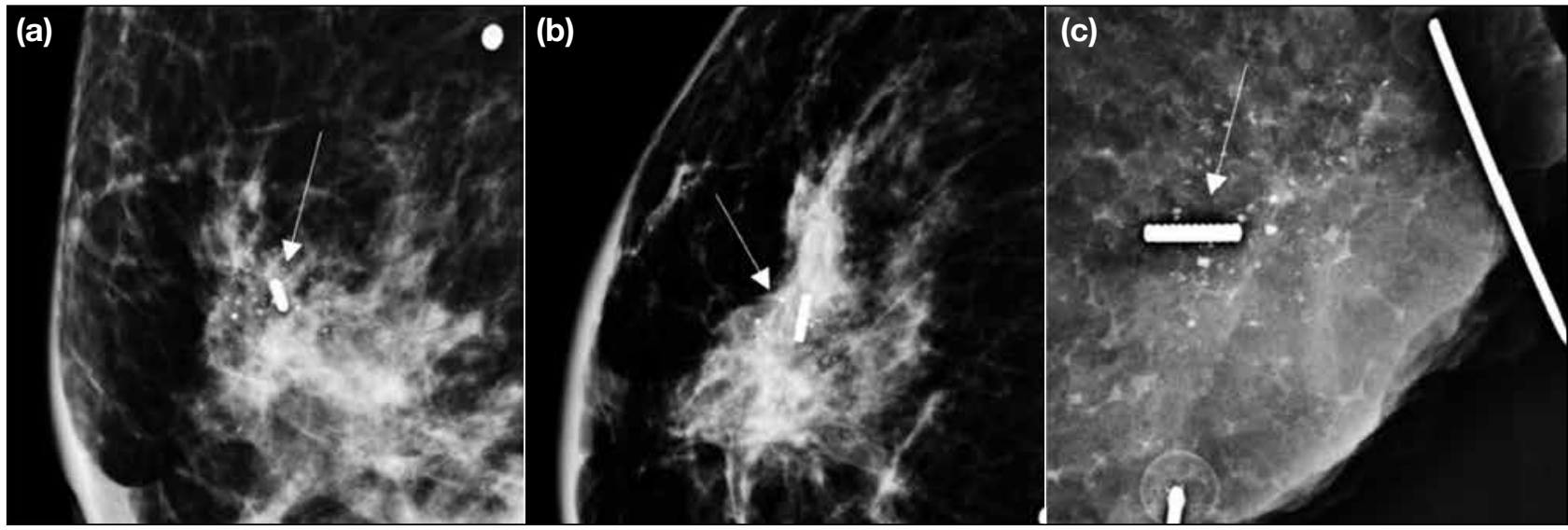

Figure 3. A 67-year-old woman with invasive carcinoma, presenting with fine pleomorphic microcalcifications in the upper outer quadrant of the right breast. Magseed was placed under stereotactic guidance. (a) Mediolateral oblique and (b) craniocaudal views of post-placement mammograms, showing Magseed (arrow) at the centre of the microcalcifications. (c) Specimen mammogram showing excision of microcalcifications and Magseed (arrow) with adequate margins. No significant displacement of Magseed seen.

surgical instruments are necessary. Electrocautery or other metallic equipment in the operating room can also interfere with the signal, requiring recalibration of the probe..$^{5}$ The surgical specimen is then sent to the radiology department for radiography or ultrasound. Further surgical exploration is performed if all markers are not identified in the specimen images.

Radioguided nonpalpable lesion localisation is performed by intratumoural injection of approximately $0.2 \mathrm{~mL}$ of $0.5 \mathrm{mCi}(18.5 \mathrm{MBq})$ technetium- $99 \mathrm{~m}\left({ }^{99 \mathrm{~m}} \mathrm{Tc}\right)$ labelled sulphur colloid using a $22 \mathrm{G}$ spinal needle under stereotactic or ultrasound guidance. Filtered ${ }^{99 m} \mathrm{Tc}$ labelled sulphur colloid, with particle dimension $<100 \mathrm{~nm}$, is used for sentinel node and nonpalpable lesion localisation in patients with biopsy-proven invasive carcinoma and high-grade ductal carcinoma in situ. An anterior planar image of the patient is then acquired at 30 minutes post-injection to confirm adequate radioactivity at the injection site and at 2 hours postinjection to identify the sentinel lymph nodes in such cases if the initial 30-minute scan is negative. The patient is operated on within 4 to 6 hours. The nonpalpable breast lesions are detected by a handheld gamma probe. Following excision, the surgical bed is checked for any residual radioactivity. The specimen is then sent to the nuclear medicine department for specimen scintigraphy and to the radiology department for radiography or ultrasound (Figure 4). Further surgical exploration is performed if residual activity remains high in the breast or if incomplete excision is noted on the specimen radiograph, ultrasound, or scintigraphic image. ${ }^{4}$
Patients' demographics, localisation indications, localisation-operation intervals, localisation procedures (image modality, approach in stereotactic guided localisation, localisation duration, lesion type, depth of lesion and size of lesion), complications, pathology reports (specimen and tumour size, margin status), operation records (operation time and intra-operative re-excision) and reoperation records were reviewed via electronic patient records. Pre-localisation mammograms (if available), specimen mammograms, ultrasounds, and scintigraphic images were also reviewed.

Technical success of the Magseed method was defined as the seed being $\leq 1 \mathrm{~cm}$ from the target in post-placement image. Magseed is considered placed within the target if there is no distance gap between the two. Displacement of the seed relative to the target during the localisationoperation interval was determined by the differences in distance between the centre of the seed and that of the target in post-placement and specimen images.

Specimen and tumour volumes were calculated by multiplying the three dimensions reported by the pathologist. To determine the breast volume, mammographic measurements were recorded and breast volume was calculated using the formula for an elliptical cone $(V=1 / 3 \pi \times r C C \times r M L O \times h M L O) .{ }^{9}$

\section{Statistical Analysis}

Simple descriptive summary statistics of the main parameters were derived. Percentages for categorical variables, means, medians and range values for 
quantitative factors were calculated as appropriate.

Continuous variables were analysed using independent $t$ tests for parametric data and the Mann-Whitney $U$ test for nonparametric data. Categorical variables were analysed using Pearson's Chi-square test or Fisher's exact test where appropriate. Statistical analysis was performed using commercial software (SPSS Windows version 23.0; IBM Corp, Armonk [NY], US). p Values were calculated, with $\mathrm{p}<0.05$ defined as significant.

\section{RESULTS}

A total of 24 lesions were localised with Magseed in 23 patients. One patient had two Magseeds placed for two lesions in the same breast that were $2.1 \mathrm{~cm}$ apart. Twenty-four ROLL lesions with matched pathology were included for comparison.

Demographics, target characteristics, and localisation techniques are shown in Table 1. Most lesions in both groups were targeted for therapeutic intent. No

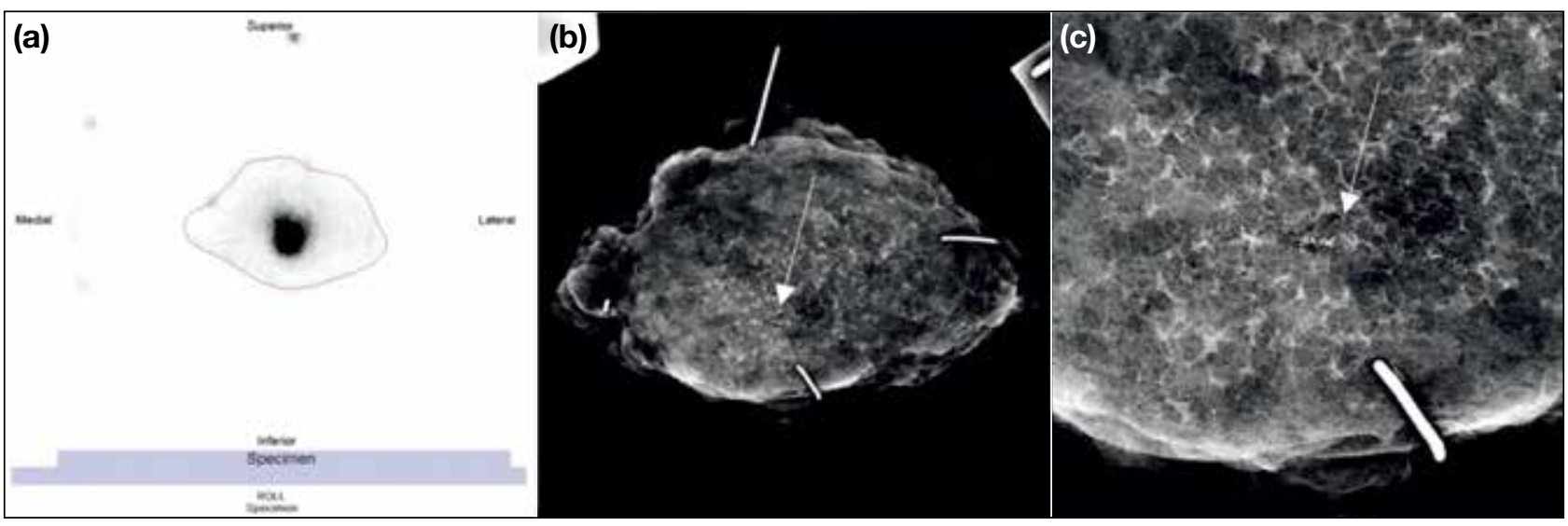

Figure 4. A 60-year-old woman with high-grade ductal carcinoma in situ, presented with a group of round and punctate microcalcifications in a linear distribution. The microcalcifications were localised along with sentinel nodes under stereotactic guidance using scintigraphy. (a) Specimen scintigraphy showing uptake of radiotracer at the centre of the specimen. (b, c) Specimen mammogram showing microcalcifications (arrow) in the corresponding region.

Table 1. Characteristics of patients and breast lesions localised with Magseed and radioisotope-guided lesion localisation.*

\begin{tabular}{|c|c|c|c|}
\hline & Magseed & $\begin{array}{l}\text { Radioisotope-guided lesion } \\
\text { localisation }\end{array}$ & $\mathrm{p}$ Value \\
\hline No. of lesions & 24 & 24 & \\
\hline Mean age, y (range) & $61(38-75)$ & $60.9(46-72)$ & 0.97 \\
\hline Median localisation-operation interval, d (range) & $0(0-14)$ & $0(0)$ & $0.005^{\star}$ \\
\hline Intent & & & 1 \\
\hline Therapeutic & $19(79.2 \%)$ & $20(83.3 \%)$ & \\
\hline Diagnostic & $5(20.8 \%)$ & $4(16.7 \%)$ & \\
\hline Mean localisation duration, min (range) & $12.9(7-20)$ & $8.7(5-19)$ & $<0.0001^{*}$ \\
\hline Modality & & & 0.233 \\
\hline Ultrasound & $11(45.8 \%)$ & $7(29.2 \%)$ & \\
\hline Stereotactic & $13(54.2 \%)$ & $17(70.8 \%)$ & \\
\hline LM & $9(69.2 \%)$ & $13(76.5 \%)$ & \\
\hline$M L$ & $3(23.1 \%)$ & $3(17.6 \%)$ & \\
\hline LM drop shoulder & - & $1(5.9 \%)$ & \\
\hline $\mathrm{CC}$ & $1(7.7 \%)$ & - & \\
\hline Median depth of target, cm (range) & $1.3(0.4-3.4)$ & $1.1(0.4-2.8)$ & 0.293 \\
\hline Median size of target, $\mathrm{cm}$ (range) & $0.8(0.1-2.5)$ & $1.1(0.1-3.8)$ & 0.269 \\
\hline Target type & & & 0.233 \\
\hline Mass & $11(45.8 \%)$ & 7 (29.2\%) & \\
\hline Calcifications & $10(41.7 \%)$ & $16(66.7 \%)$ & \\
\hline Marker & $2(8.3 \%)$ & - & \\
\hline Co-ordinates & 1 (4.2\%) & $1(4.2 \%)$ & \\
\hline
\end{tabular}

Abbreviations: $\mathrm{CC}=$ craniocaudal; $\mathrm{LM}=$ lateromedial; $\mathrm{ML}=$ mediolateral.

* Data are shown as No. (\%), unless otherwise specified. 
complications related to Magseed insertion or ROLL injection were reported. Same-day surgery was performed in all lesions localised with radioisotope guidance and in 17 Magseed-localised lesions. The localisation-operation interval for the other seven Magseed lesions was 4 to 14 days.

Surgical outcomes are listed in Table 2. All nonpalpable breast lesions were successfully identified and excised using the predetermined localisation technique except for two Magseed lesions. Both cases were planned for same-day surgery, but the Magseeds were displaced from the target after placement. One was displaced $1.6 \mathrm{~cm}$ and the other $1.7 \mathrm{~cm}$. A hookwire was placed to target the lesions in both instances after discussion with surgeons. The target, hookwire and Magseed were successfully retrieved during the surgeries (Figure 5). Since these lesions were localised with hookwire rather than Magseed, these lesions were excluded from the tumour analysis in Magseed group.

Magseed and ROLL procedural parameters are listed in Tables 3 and 4, respectively. Minimal displacement of Magseeds was observed in two cases during the localisation-operation interval. Both cases were operated on the same day. In the rest of the cases that were operated on 4 to 14 days post-placement, the displacement was up to $2.7 \mathrm{~mm}$. Four Magseeds were dislodged from the specimen either during surgery or during transfer to the radiology department. Therefore, the distance between the target and Magseed could not be measured and they were excluded from the analysis.

The mean operation times were comparable in both groups, being $92.1 \mathrm{~min}$ in Magseed group and $96.5 \mathrm{~min}$ in the ROLL group $(\mathrm{p}=0.461)$. The intraoperative reexcision rate was significantly lower in the Magseed group (8.3\%) compared with the ROLL group (45.8\%, $\mathrm{p}=0.006)$ The re-excision rate was $20.8 \%$ in the Magseed group and 33.3\% in ROLL group $(\mathrm{p}=0.425)$.

Five Magseed and two ROLL lesions had no preoperative mammograms performed in our hospital as they were performed in other hospitals or outside facilities. They were thus excluded from the breast volume analysis. Table 2 shows the breast, specimen, and tumour volumes were not significantly different between the two groups.

Table 2. Surgical outcomes of breast lesions in Magseed and radioisotope-guided lesion localisation groups. *

\begin{tabular}{|c|c|c|c|}
\hline & Magseed & $\begin{array}{l}\text { Radioisotope-guided lesion } \\
\text { localisation }\end{array}$ & $\mathrm{p}$ Value \\
\hline Mean operation time, min (range) & $92.1(45-145)$ & $96.5(45-205)$ & 0.461 \\
\hline Median breast volume, $\mathrm{cm}^{3}$ (range) & $763.1(403.5-1998.3)$ & $602.5(238-1361.9)$ & 0.123 \\
\hline Median specimen volume, $\mathrm{cm}^{3}$ (range) & $47.3(15-117.5)$ & $70(15-260.3)$ & 0.257 \\
\hline Median tumour volume, $\mathrm{cm}^{3}$ (range) & $1(0.064-15.6)$ & $0.88(0.125-12.2)$ & 0.702 \\
\hline Median closest margin, mm (range) & $2.2(1-5)$ & $4.5(1-8)$ & 0.082 \\
\hline Preoperative pathological diagnosis & & & 1 \\
\hline Malignancy or high-risk lesions & $22(91.7 \%)$ & $23(95.8 \%)$ & \\
\hline Ductal carcinoma in situ & 7 & 7 & \\
\hline Invasive carcinoma & 10 & 12 & \\
\hline Tubular carcinoma & 2 & 1 & \\
\hline Encapsulated papillary carcinoma & - & 2 & \\
\hline Atypical ductal hyperplasia & 1 & 1 & \\
\hline Borderline phyllodes & 2 & - & \\
\hline Others & $2(8.3 \%)$ & $1(4.2 \%)$ & \\
\hline Intraductal papilloma & - & 1 & \\
\hline Benign & 2 & - & \\
\hline Margin involvement & & & 1 \\
\hline No & $12(50 \%)$ & $16(66.7 \%)$ & \\
\hline Yes & $6(25 \%)$ & $8(33.3 \%)$ & \\
\hline Intraoperative re-excision rate & & & $0.006^{*}$ \\
\hline No & $20(83.3 \%)$ & $13(54.2 \%)$ & \\
\hline Yes & $2(8.3 \%)$ & $11(45.8 \%)$ & \\
\hline Re-operation rate & & & 0.425 \\
\hline No & $17(70.8 \%)$ & $16(66.7 \%)$ & \\
\hline Yes & $5(20.8 \%)$ & $8(33.3 \%)$ & \\
\hline
\end{tabular}

* Data are shown as No. (\%), unless otherwise specified. 

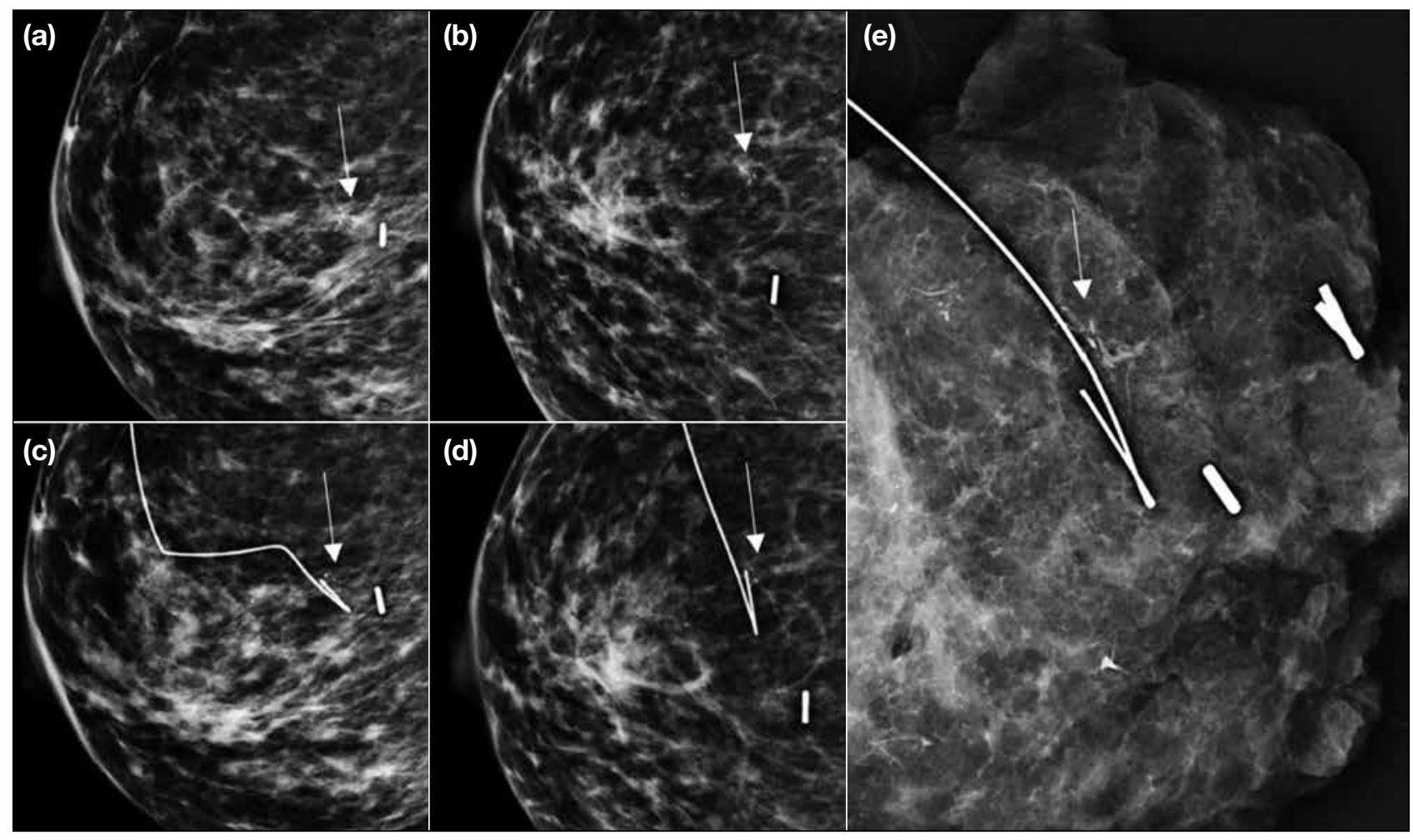

Figure 5. A 69-year-old woman with high-grade ductal carcinoma in situ, presenting with a group of microcalcifications at central subareolar posterior part of the right breast. (a) Mediolateral (ML) and (b) craniocaudal (CC) mammographic views with Magseed placed under stereotactic guidance. The Magseed was displaced $16 \mathrm{~mm}$ medially from the microcalcifications (arrows). (c) ML and (d) CC views of right mammogram showing hookwire placement, targeting the microcalcifications (arrows). (e) Specimen mammogram showing excision of microcalcifications (arrow), together with hookwire and Magseed.

In all, 22 out of 24 Magseed lesions were malignant or high-risk lesions in the preoperative core biopsy pathology report. A patient whose two ultrasounds detected Breast Imaging-Reporting and Data System 4A lesions had core biopsy result of benignity but she underwent excisional biopsy due to radiologicalclinical discordance. Two Magseeds were placed $2.1 \mathrm{~cm}$ apart. Both lesions were successfully resected with the Magseed. Final pathology came back benign. In another Magseed case, a preoperative diagnosis of invasive ductal carcinoma was made with stereotactic-guided biopsy of microcalcifications. The patient underwent neoadjuvant chemotherapy and subsequent Magseed localisation and breast-conserving surgery. The microcalcifications were successfully localised with the Magseed $4.2 \mathrm{~mm}$ from the target. The pathological report showed no residual tumour within the specimen. In another Magseed case, a preoperative diagnosis of tubular carcinoma was made with stereotactic biopsy of microcalcifications. The microcalcifications were successfully localised with a Magseed $2 \mathrm{~mm}$ from the target. The pathological report, however, showed no malignancy. Therefore, margin clearance of these lesions was not included in the analysis. In total, 23 out of 24 lesions identified with ROLL showed malignant or high-risk lesions. Margin clearance of lesions was $66.7 \%$ in both Magseed and ROLL groups.

\section{DISCUSSION}

Successful management of nonpalpable breast lesions depends on accurate preoperative localisation. Various previous studies have shown the effectiveness of Magseed as a convenient method for nonpalpable breast lesion localisation. ${ }^{8,10-12}$ However, to our knowledge, no published studies have compared Magseed with ROLL. Our study is the first study to show comparable results between Magseed and ROLL in terms of operation time, surgical specimen size, margin clearance and reoperation rate. Magseed is superior with a significantly reduced intraoperative re-excision rate as well as allowing decoupling of localisation and operation schedules. Although the majority of the Magseed cases 
Table 3. Procedural parameters of breast lesions in Magseed group.*

\begin{tabular}{lccc}
\hline & Overall & Ultrasound & Stereotactic \\
\hline No. of lesions & $24(100 \%)$ & $11(45.8 \%)$ & $13(54.2 \%)$ \\
Localisation-operation interval, d & 17 & 7 & 10 \\
$\quad 0$ & 2 & 1 & 1 \\
4 & 2 & 2 & - \\
6 & 2 & 1 & - \\
7 & 1 & $0.3(0-4.2)$ & $0.3(0-4.8)$ \\
$\quad 14$ & $0.3(0-4.8)$ & $0(0-1.3)$ & $2(0-17)$ \\
Median displacement during localisation-operation & & $11(100 \%)$ & $11(84.6 \%)$ \\
interval, mm (range) & $0.05(0-17)$ & 0 & $2(15.4 \%)$ \\
Median distance after deployment, mm (range) & $22(91.7 \%)$ & $10(90.9 \%)$ & $4(30.8 \%)$ \\
Technical success & $2(8.3 \%)$ & $1(9.1 \%)$ & $9(69.2 \%)$ \\
$\quad$ Yes & $14(58.3 \%)$ & & \\
No & $10(41.7 \%)$ & & \\
Magseed placed within target & & & \\
$\quad$ Yes & & & \\
No & & & \\
\hline
\end{tabular}

* Data are shown as No. (\%), unless otherwise specified.

Table 4. Procedural parameters of breast lesions in radioisotope-localisation group. *

\begin{tabular}{llcc}
\hline & Overall & Ultrasound & Stereotactic \\
\hline $\begin{array}{l}\text { No. of lesions } \\
\text { Localisation-operation interval }\end{array}$ & $24(100 \%)$ & $7(29.2 \%)$ & $17(70.8 \%)$ \\
$\quad 0 d$ & 24 & 7 & 17 \\
Technical success & & $7(100 \%)$ & $17(100 \%)$ \\
Yes & $24(100 \%)$ & 0 & 0 \\
No & 0 & & \\
\hline
\end{tabular}

* Data are shown as No. (\%), unless otherwise specified.

were operated on the same day, 29.2\% (7/24) cases were operated 4 to 14 days post-Magseed localisation and no significant displacement of the Magseed was observed during the localisation-operation interval. This is more efficient in workflow and allows flexibility in appointment arrangement. The localisation procedure can be performed days to weeks before surgery, eliminating the need for coordination between radiology, nuclear medicine departments, and operating theatres and thus reducing any possible delays in surgery due to difficult localisation or waste of resources due to cancelled cases. In addition, Magseed has no radiation. The results of this study suggest that Magseed can be used to replace ROLL.

In our study, 20.8\% Magseed cases require reoperation due to positive margins. It is similar to previous published studies. In a study by Lamb et al,,$^{10} 21.9 \%$ tumourpositive or close surgical margins requiring re-excision. In another study by Price et al, ${ }^{11} 17.2 \%$ malignant cases had positive or close margin.
The localisation duration was shorter for the ROLL technique in our study. As Magseed is a new localisation technique, we postulate there is a learning curve for radiologists to adapt to this new method. Deploying Magseed is similar to marker placement. With more practice, the localisation duration will likely be shortened. In addition, patients undergoing ROLL need to be transferred to the nuclear medicine department for scintigraphy, whose time needed for transfer and scanning were not included in the calculation. Magseed patients, on the other hand, do not need to be transferred to the nuclear medicine unit for scintigraphy, which contributes to a shorter overall preoperative localisation duration.

In our study, we achieved $100 \%$ technical success rate in Magseed placement under ultrasound guidance. Technical success of Magseed was lower in stereotactic placement $(84.6 \%)$ with two cases showing significant Magseed displacement, namely $16 \mathrm{~mm}$ and $17 \mathrm{~mm}$ from the target. These were observed in our 5 th and 
8th stereotactically guided cases. We believe this occurred due to the accordion effect, which is also not uncommonly seen in marker clip placement after stereotactic biopsy. ${ }^{13-18}$ In subsequent cases, we attempted to maintain manual breast compression over the Magseed insertion site upon releasing the paddle compression. The manual breast compression was then slowly released. Technical success was achieved in the remaining five stereotactic cases using this manoeuvre. Minimal displacement of a Magseed up to $4.8 \mathrm{~mm}$ was observed during the localisation-operation interval. No previous published studies related to Magseed had documented any significant or late migration of Magseed during the localisation-operation interval. Movement of Magseed could occur while it was in the breast or after it was excised. It could be related to inconsequential movement of Magseed within the breast after placement, or manipulation by surgeons during or after operation, when the architectural support from surrounding breast tissues is lost. Furthermore, displacement of Magseed was insignificant and did not affect the accuracy of localisation during operation, excision of the nonpalpable breast lesions or the overall performance.

There was one case in each Magseed and ROLL groups where the microcalcifications were too faint to be identified on the prone biopsy table. Therefore, the previous biopsy scar, stereotactic biopsy position, breast compression thickness, and coordinates in previous biopsy were used as reference. Both cases resulted in successful localisation and excision with the surgical specimen pathology matching the one biopsied. We suggest placement of a marker clip after biopsy if the microcalcifications are too faint to be identified during and after biopsy, in order to aid further localisation if needed.

Constraints with ROLL have been previously documented, such as inaccurate injections of isotopes in a compressed breast (especially thin ones) ductal migration of isotopes, the need of a nuclear medicine department and timely transfer to operation theatres. ${ }^{4}$ Magseed also has its limitations. Non-magnetic surgical equipment and retractors need to be used to eliminate any possible interference with the detection probe, which can be a limitation. Economical concern is also a part of considerations for some institutions as Magseed is more expensive than ROLL.

Just as precise localisation of nonpalpable breast lesions is essential, accurate localisation of sentinel lymph nodes is equally important. In a prospective, multicentre and multinational study by Thill et al ${ }^{19}$ Sienna dye, a magnetic tracer with superparamagnetic iron oxide compound and particle dimensions of $60 \mathrm{~nm}$, was used for sentinel lymph node localisation and biopsy. It was compared with ${ }^{99 \mathrm{~m}} \mathrm{Tc}$ filtered sulphur colloid, which is the traditional standard to localise sentinel lymph node. The study included 150 patients in each group and showed comparable result between Sienna dye and radioisotope. ${ }^{19}$ The Sienna dye can be injected by the surgeons in the operation room at least 20 minutes before sentinel lymph node biopsy and is detected with the Sentimag probe. Therefore, in Magseed cases, it is possible to perform sentinel lymph node mapping with the same probe in the same session with the use of Sienna dye during surgery.

There are several limitations to our study. This was a retrospective review with a small patient sample size from a single institution. It revealed our early experience with a new technique, and both the radiologists and surgeons involved were new to this method. The decision of Magseed localisation or ROLL was determined during combined clinical and radiological meetings with surgeons. The preference of surgeons might impose a selection bias. Larger multi-institutional prospective randomised studies would be necessary to fully compare Magseed with ROLL.

\section{CONCLUSION}

We have shown that Magseed is a safe and effective localisation technique for breast lesion localisation, and superior to ROLL as it is non-radioactive and allows decoupling of radiological and surgical schedules. This study showed results in operation time, margin clearance, and reoperation rate comparable to those of ROLL.

\section{REFERENCES}

1. Lui CY, Lam HS, Chan LK, Tam KF, Chan CM, Leung TY, et al. Opportunistic breast cancer screening in Hong Kong; a revisit of the Kwong Wah Hospital experience. Hong Kong Med J. 2007; 13:10613.

2. Sitt JC, Lui C, Sinn LH, Fong JC. Understanding breast cancer screening - past, present, and future. Hong Kong Med J. 2018;24:166-74.

3. Corsi F, Sorrentino L, Bossi D, Sartani A, Foschi D. Preoperative localization and surgical margins in conservative breast surgery. Int J Surg Oncol. 2013;2013:793819.

4. Chu TY, Lui CY, Hung WK, Kei SK, Choi CL, Lam HS. Localisation of occult breast lesion: a comparative analysis of hookwire and radioguided procedures. Hong Kong Med J. 2010;16:367-72.

5. Jeffries DO, Dossett LA, Jorns JM. Localization for breast surgery: the next generation. Arch Pathol Lab Med. 2017;141:1324-9. 
6. Magseed magnetic marker receives FDA clearance for long-term and soft tissue implantation [Internet]. Available from: https:// www.mammotome.com/wp-content/uploads/2018/03/MagseedIndication-Press-Release.pdf. Accessed 14 Jun 2020.

7. Endomagnetics Ltd (Endomag). Indications for use. Available from: https://www.endomag.com/indications-for-use/. Accessed 9 Nov 2020.

8. Harvey JR, Lim Y, Murphy J, Howe M, Morris J, Goyal A, et al. Safety and feasibility of breast lesion localization using magnetic seeds (Magseed): a multi-centre, open-label cohort study. Breast Cancer Res Treat. 2018;169:531-6.

9. Fung JT, Chan SW, Chiu AN, Cheung PS, Lam SH. Mammographic determination of breast volume by elliptical cone estimation. World J Surg. 2009;34:1442-5.

10. Lamb LR, Bahl M, Specht MC, D'Alessandro HA, Lehman CD. Evaluation of a nonradioactive magnetic marker wireless localization program. AJR Am J Roentgenol. 2018;211:940-5.

11. Price ER, Khoury AL, Esserman LJ, Joe BN, Alvarado MD. Initial clinical experience with an inducible magnetic seed system for preoperative breast lesion localization. AJR Am J Roentgenol. 2018;210:913-7.

12. Zacharioudakis K, Down S, Bholah Z, Lee S, Khan T, Maxwell AJ, et al. Is the future magnetic? Magseed localisation for non-palpable breast cancer. A multi-centre non randomised control study. Eur J
Surg Oncol. 2019;45:2016-21.

13. Burbank F, Forcier N. Tissue marking clip for stereotactic breast biopsy: initial placement accuracy, long-term stability, and usefulness as a guide for wire localization. Radiology. 1997;205:407-15.

14. Liberman L, Dershaw DD, Morris EA, Abramson AF, Thornton CM, Rosen PP.Clip placement after stereotactic vacuum-assisted breast biopsy. Radiology. 1997;205:417-22.

15. Burnside ES, Sohlich RE, Sickles EA. Movement of a biopsy-site marker clip after completion of stereotactic directional vacuumassisted breast biopsy: case report. Radiology. 2001;221:504-7.

16. Rosen EL, Vo TT. Metallic clip deployment during stereotactic breast biopsy: retrospective analysis. Radiology. 2001;218:5106.

17. Philpotts LE, Lee CH. Clip migration after 11-gauge vacuumassisted stereotactic biopsy: case report. Radiology. 2002;222:7946.

18. Esserman LE, Cura MA, DaCosta D. Recognizing pitfalls in early and late migration of clip markers after imaging-guided directional vacuum-assisted biopsy. Radiographics. 2004;24:147-56.

19. Thill M, Kurylcio A, Welter R, van Haasteren V, Grosse B, Berclaz G, et al. The Central-European SentiMag study: Sentinel lymph node biopsy with superparamagnetic iron oxide (SPIO) vs. radioisotope. Breast. 2014;23:175-9. 